\title{
Modos críticos de construcción de la teoría. Reflexiones desde Arturo Roig y Homi Bhabha
}

\section{Critical modes for theory construction. Reflections by Arturo Roig and Homi Bhabha}

\section{Modos críticos de construção da teoria. Reflexões desde Arturo Roig e Homi Bhabha}

\author{
Dra. Paula Cristina Ripamonti ${ }^{1}$ \\ Lic. Patricia Yori
}

Recibido: 20 de julio de 2018 - Aceptado: 27 de agosto de 2018

\begin{abstract}
Resumen
En el vasto campo de las disciplinas sociales y humanísticas, la discusión epistemológica acerca de las condiciones de la producción intelectual es intensa. Sin embargo, no siempre se explicita el lugar de enunciación. Desde la tradición occidental, estamos familiarizados/as con escrituras con un sujeto de la enunciación monológico y neutralizado, situado a distancia de sus propias tramas vitales y políticas. En nuestro artículo abordamos dos modos de comprender el ejercicio teórico de construcción de la realidad social que abren perspectivas divergentes a las hegemónicas. Se trata de la ampliación metodológica en la historia de las ideas latinoamericanas de Arturo Roig y la perspectiva de Homi Bhabha, que toma como punto de partida la hibridez cultural e histórica del mundo
\end{abstract}

1 Argentina, profesora y doctora en Filosofía (UNCuyo-Argentina), especialista en Docencia universitaria y postitulada en Investigación educativa (CEA- UNCórdoba). Se desempeña como docente adjunta efectiva de "Antropología filosófica" en la Facultad de Filosofía y Letras de la Universidad Nacional de Cuyo. Contacto: paulafilo70@gmail.com.

ORCID: https://orcid.org/0000-0003-0187-1273

2 Argentina, licenciada y profesora en Filosofía (UNCuyo-Argentina), postitulada en Investigación educativa (CEA- UNCórdoba) y maestranda de la Maestría de Estudios Latinoamericanos (UNCuyo-Argentina). Se desempeña como docente titular en el Instituto de Educación Superior 9-001 (Mendoza, Argentina). Contacto: patriciayori@ gmail.com.

ORCID: https://orcid.org/0000-0002-8086-9528 
poscolonial. El recorrido busca mostrar y tensionar estas dos posiciones, que ofrecen diferentes claves para pensar la praxis teórica.

Palabras clave: Arturo Roig - Homi Bhabha - teoría - historia de las ideas - poscolonialidad

\begin{abstract}
In the vast field of social and humanistic disciplines, the epistemological discussion about conditions of intellectual production is intense. However, the place of enunciation is not always explicit. From the Western tradition, we are familiar with scriptures with a subject of monologized and neutralized enunciation, located at a distance from their own vital and political plots. In our article we approach two ways of understanding the theoretical exercise of construction of social reality that open perspectives divergent to hegemonic ones. It deals with the methodological extension in the history of Latin American ideas by Arturo Roig and the perspective of Homi Bhabha, taking as starting point the cultural and historical hybridity of the postcolonial world. The text seeks to show and stress these two positions, offering different keys to think about theoretical praxis.
\end{abstract}

Keywords: Arturo Roig - Homi Bhabha - theory - history of ideas postcolonialism

\title{
Resumo
}

No vasto campo das disciplinas sociais e humanísticas, a discussão epistemológica sobre as condições da produção intelectual é intensa. No entanto, não sempre se explicita o lugar de enunciação. Desde a tradição ocidental, estamos familiarizados/as com escritas com um sujeito da enunciação monológico e neutralizado, situado à distância de suas próprias tramas vitais e políticas. Em nosso artigo abordamos dois modos de compreender o exercício teórico de construção da realidade social que abrem perspectivas divergentes às hegemônicas. Trata-se da ampliação metodológica na história das ideias latino-americanas de Arturo Roig e a perspectiva de Homi Bhabha, que toma como ponto de partida a hibridez cultural e histórica do mundo pós-colonial. O percurso busca mostrar e tensionar estas duas posições, que oferecem diferentes chaves para pensar a práxis teórica.

Palavras-chave: Arturo Roig - Homi Bhabha - teoria - história das ideias - pós-colonialidade 


\section{Introducción}

En el vasto y heterogéneo campo de las disciplinas sociales y humanísticas, la discusión epistemológica acerca de las condiciones concretas desde, en o a través de las cuales problematizamos e interpretamos el mundo social, es intensa. En toda práctica intelectual no sólo tomamos decisiones respecto de determinados abordajes teóricos y metodológicos, sino también ponemos en juego modos de leer, de afirmar y negar, de configurar el lugar y tiempo desde los cuales hablamos. Sin embargo, en las producciones intelectuales no siempre aparece de forma explícita el modo en que nos implicamos. Desde la tradición occidental y su epistemología eurocéntrica, hemos naturalizado escrituras en las que el sujeto de la enunciación está "borrado" (Castro-Gómez 2005) y se presenta de modo monológico, neutralizado, despojado de toda carnadura, etnicidad, historia, sexualidad, clase social, poder, alejado de sus propias tramas vitales y políticas. Lo que resulta "borrado" es, sin duda, las condiciones materiales en las que emergen, su inscripción en los dispositivos saber-poder y las legitimidades que los sujetos ponen en juego.

Por otra parte, la categoría "totalidad social" en la que se apoyaron las teorías críticas de base marxista ha sufrido sucesivas resemantizaciones e incluso su disolución en el decurso crítico de la modernidad. El giro actual hacia el análisis cultural y el énfasis puesto en la diversidad, constituyen un logro en las luchas antihegemónicas al dominio occidental de la modernidad. Recordemos que, a lo largo del siglo $\mathrm{XX}$, en el mismo seno de la modernidad europea, se desarrollaron teorías disidentes que fueron radicalizando su crítica a la noción de razón universal y trascendental como fundamento del conocimiento. Entre ellas encontramos desde la Escuela de Frankfurt al posestructuralismo, desde las denominadas corrientes posmodernistas hasta la crítica poscolonial o los Estudios Culturales latinoamericanos. A pesar de sus muchas diferencias, estos desarrollos tienen en común el avance progresivo hacia el desfondamiento de la estructuración práctica o teórica; el predominio de una actitud estética, el abandono de la categoría de sujeto, la ausencia de una teoría que permita pensar la praxis colectiva transformadora a partir 
de su propia historia, el desarrollo de análisis capilares del poder y la concepción del carácter fragmentario, heterogéneo y plural de la realidad. Particularmente, los Estudios Culturales (EC), se conciben como un movimiento transdisciplinario que resulta de la actividad crítica de los intelectuales en el marco de la condición posmoderna ${ }^{3}$. Se conforman como una alternativa a la sociología, la antropología, la comunicología y la crítica literaria, con el objeto privilegiado de investigar la cultura. Estos estudios surgen en un momento en que los grandes ejes de identificación colectiva, como eran las nacionalidades, entran en crisis por los efectos culturales de la globalización. Paralelo a esto, se advierten procesos de "hibridación" de culturas. Los EC se inician con un potencial crítico y denunciante de estas situaciones y toman un giro semiológico y textualista cada vez más especulativo. Los temas de interés son el género y sexualidad, la identidad cultural, el colonialismo y el poscolonialismo, la raza y la etnicidad, la pedagogía, la globalización cultural, el discurso y la textualidad, entre los más tratados ${ }^{4}$.

En este contexto, analizamos dos pensadores, uno latinoamericano y otro indio, que hacia finales del siglo XX gestaron posiciones críticas respecto de las filosofías posmodernas que diluían las categorías de "sujeto", "historia" y "verdad" en diferentes versiones. En un contexto de crisis de la razón, ambos intervinieron aquel "pensamiento débil"

3 Aquí "transdisciplinario" alude a la conformación de un modo de trabajo epistémico y metodológico que reclama interacción de elementos de diversas disciplinas en vistas a un objeto de estudio nuevo, no previsto como tal desde sus matrices específicas. Sin embargo, no se trata de posicionarse por afuera de las miradas disciplinares, sino de moverse desde y a través de ellas por la exigencia misma de los problemas propuestos para pensar y analizar.

4 Un buen texto para ampliar es el editado por Nelly Richard, En torno a los estudios culturales. Trayectorias, localidades y disputas (2010).

5 Una expresión que se asocia a los teóricos de la posmodernidad es la de "pensamiento débil". Esta expresión fue acuñada Gianni Vattimo (1990) para designar a aquellas teorías que afirman que un proceso análogo al que aparece en el lenguaje publicitario se presenta en todos los órdenes del discurso (cotidiano, científico y cultural). Es decir, las palabras manifiestan un sentido en relación con la situación afectiva o vivencial de la persona o personaje; por lo tanto, carece de sentido buscar una fundamentación profunda que justifique las obras y las concepciones humanas. 
y se introdujeron de lleno en la preocupación por la praxis social y política, las posibilidades teóricas y su performatividad, es decir, la potencia ético-política de los discursos.

En esta línea, Arturo Roig desarrolla una "teoría y crítica" del pensamiento latinoamericano cuyas claves epistemológicas postulan posiciones en torno a la afirmación de la subjetividad y la historicidad (Ripamonti 2014). Estas claves fueron esgrimidas por Roig en el contexto de las últimas décadas del siglo XX, en el marco de discusiones acerca de la legitimidad de los saberes que producimos en América Latina, poniendo especial atención en los contextos de producción. En grandes rasgos, su propuesta pone énfasis en el sujeto colectivo de las ideas, en la historicidad de la producción intelectual y el modo de contextualizar dicha producción en la materialidad de las prácticas institucionales y cotidianas. Además, por el modo de referenciar las ideas en procesos identitarios de dimensión política e ideológica.

Desde otros recorridos, avanzada la década de los 90, Homi Bhabha se destaca dentro de la perspectiva de los Estudios Culturales poscoloniales. Si bien hay cierto consenso en considerar la colonialidad del poder, de matriz eurocéntrica, como una forma de dominación que sobrevive a los procesos de colonización (Quijano 2014), no se trata de una "una empresa monolítica, un proyecto sin fisuras y homogéneo" (Dube 1999 s/n). Del mismo modo, son diversos los proyectos de interpelación y ruptura a esta matriz. Encontramos diferentes elaboraciones críticas, dentro de las cuales Bhabha es una de esas voces. Él entiende que se trata de comprender de otro modo la teoría, desplazarla de los emplazamientos eurocentrados en los que ha quedado cooptada, en particular como "una visión totalizante utópica del Ser y de la Historia que busca trascender las contradicciones y ambivalencias" "de la sub-

En este sentido, no hay que buscar significados últimos de las cosas, el significado siempre consistiría en la proyección de una parcial interpretación propia y personal. Los aspectos más sobresalientes de esta perspectiva son la valoración del disenso y la divergencia; la valoración de la diversidad cultural y desarrollo o promoción de grupos contraculturales; la concepción de una multiplicidad de formas de pensar; el pluralismo y el desarrollo de los estudios culturales. 
jetividad humana y sus sistemas de representación cultural" (Bhabha 2002 39). Por esto interroga las formaciones culturales que arraigan en los bordes o grietas de los espacios políticos institucionalizados y que implican procesos de identificación intersticiales. Pone el foco en el funcionamiento de las ideas políticas de la tradición occidental, como justicia, libertad, razón y representación, en contextos habitados por actores subalternos.

En este trabajo nos interesa desarrollar algunos matices epistemológicos que adquiere el desarrollo teórico en ambos intelectuales. Buscamos mostrar dos formas de comprender ese quehacer y cómo en ambas se impugna la teoría como metalenguaje de la totalidad entendida de forma hipostasiada, de tal modo que las diferencias entre una y otra derivan de la índole de sus preocupaciones históricopolíticas, de las ampliaciones que buscan operar para resituar el lugar y el compromiso de la teoría. En el caso de Arturo Roig, la intervención crítica rescata una sujetividad plural como lugar de enunciación y pieza clave para una filosofía que articula la facticidad social y la denuncia de las relaciones de opresión en América Latina. En el caso de Homi Bhabha, su pensamiento articula la trama heterogénea de la configuración identitaria para rescatar la posibilidad en el tiempoespacio de la historia, en términos relacionales de hibridez, traducción y negociación.

\section{Arturo Roig y cómo hacer "teoría y crítica"}

El pensamiento de Arturo Andrés Roig incorpora elementos de renovación metodológica en el marco de la historia de las ideas latinoamericanas. Los antecedentes del mencionado campo los podríamos ubicar, en primer lugar, en la polémica entre el peruano Augusto Salazar Bondy (1968) y el mexicano Leopoldo Zea (1969) respecto de la especificidad de la práctica del filosofar en América Latina y, en segundo término, en la reunión de intelectuales convocada por la UNESCO en México, en 1974, que derivó en una serie de recomendaciones de carácter epistémico-metodológico (Arpini 2004 71). La 
agenda de esa reunión, de inspiración gaosiana ${ }^{6}$, puso el foco en la función social del pensamiento frente al purismo académico, en una apertura al análisis ideológico e interdisciplinario para abordar los problemas concretos latinoamericanos. Las ideas fueron entendidas como acciones históricas que los hombres realizan en determinadas circunstancias, inscriptas en estructuras más amplias y a través de diversas manifestaciones: filosofemas, vivencias, ideologías, concepciones del mundo, etc. El nudo gordiano de la relación teoría y praxis social fue planteado desde una matriz dialéctica; desde ella, los procesos históricos, articulados en la tensión dominación-liberación, pueden dar lugar a la integración como horizonte que tracciona la transformación social.

Arturo Roig recupera críticamente los aportes de la semiótica, la teoría del texto y la teoría crítica de las ideologías, para formular categorías teóricas del pensar y analizar la constitución histórica del sujeto latinoamericano. Desarrolla una propuesta de ampliación material y práctica en la que el texto y otras formas de producción simbólica se constituyen en un histórico y renovado archivo. De este modo, el ejercicio teórico es una práctica de lectura, una hermenéutica histórica y crítica que, desde coordenadas pragmáticas, visibilizan una situación de dependencia, de conflictividad social, de luchas emergentes contra formas derivadas de alienación. Así, el lenguaje es una vía de objetivación de la realidad social, cuyo nivel primario es la vida cotidiana. La lectura nos permite ingresar al "universo discursivo"7, a la trama semiótica de contradicciones y conflictividades en un lugar y una época determinada. "Un texto es una de las tantas manifestaciones

\footnotetext{
6 Los elementos de renovación metodológica que se desprenden del historicismo de José Gaos son: la comprensión de las ideas del pasado a partir de la situación de diálogo entre sujetos diferentes desde sus respectivas circunstancias (autor e historiador) y la concepción del fenómeno de la mediación como un proceso por el cual el sujeto histórico objetiva el mundo.

7 Roig se refiere con esta categoría a "la totalidad actual o posible de los discursos correspondientes a un determinado grupo humano en una época dada (sincrónicamente) o a lo largo de un cierto período (diacrónicamente) y sobre cuya base se establece, para esa misma comunidad, el complejo mundo de la intercomunicación" (Roig 1984 5).
} 
posibles de aquel universo" (Roig 1993 110) que expresa una dualidad, entendida como tensión y ensamble con la praxis social.

Roig busca superar el formalismo, poniendo en tensión la "dialéctica real" con la "dialéctica discursiva", en una particular relación entre texto/contexto, discursos/sujetos del discurso (Roig 1984 1993). Desde esa brecha podemos comprender y decodificar la existencia de diferentes discursos: aquellos que justifican los valores del orden vigente (discursos justificadores) o los invierten meramente (anti-discursos), y aquellos que desde la crítica proyectan una liberación del orden actual, una transformación del sistema de relaciones materiales y simbólicas vigentes (discursos contrarios). Tanto en el contenido como en la forma de los discursos encontramos lo ideológico, esto porque ambos están relacionados con el sistema de códigos que lo organizan, como con la praxis social, política, económica. Roig incluye, además, lo que denomina las funciones ideológicas y sociales del discurso. Entre las funciones ideológicas identifica la de "apoyo", que consiste en privilegiar ciertos discursos remitiéndolos a un fundamento último o absoluto y las operaciones de "historización/ deshistorización" que son aquellas que, o bien visibilizan la compleja inscripción histórica de la facticidad social, o bien ocultan el carácter histórico de la misma (Arpini 2003 78). Por su parte, las funciones sociales del discurso se desagregan en relación con el tiempo que se acentúa en el discurso. De este modo, se puede distinguir la función integradora, que articula el presente y lo valora positivamente; la función apocalíptica, que encuentra en el pasado los acontecimientos fundantes cuyo sistema de valores debería preservarse, y la función utópica, que organiza el discurso sobre ideas reguladoras que traccionan hacia el futuro, como tiempo/lugar de la transformación, de la emergencia, de la novedad. Esta función utópica no debe confundirse con las utopías. El modo como se ejerce esa función tiene que ver con los modos de objetivación de la utopía, la que puede manifestarse como narrativa descriptiva o utopías expresadas en fórmulas breves.

El análisis de los textos, en cuanto expresan y articulan la compleja facticidad social, abre la posibilidad de denunciar totalidades ideológicas cerradas y de construir un saber crítico, de liberación, situado 
y abierto. De este modo, hacer "teoría y crítica" es un acto político de toma de posición axiológica. De aquí que también Roig se refiera al pensamiento latinoamericano como un saber de vida, de carácter conjetural, es decir abierto, histórico y emancipatorio, lo cual no significa vagabundeo ideológico sino construcción teórica.

El punto de partida de la crítica se asienta en el "a priori antropológico", cuya significación consiste en: "Querernos a nosotros mismos como valiosos y consecuentemente tener como valioso el conocernos a nosotros mismos" (Roig 1981 11). Este a priori remite a un sujeto empírico y plural cuya temporalidad no se funda en la interioridad de la conciencia, sino en la historicidad como capacidad de todo hombre de gestar su propia vida. Lo primero, según Roig, es la empiricidad del sujeto. A partir de esa empiria, encarnada en la historia, cada "nosotros" se abre a la comprensión del mundo. La historia es posible en tanto el a priori antropológico no es un "yo" sino un "nosotros" y se origina en la comprensión del mundo del que parte ese "nosotros". De acuerdo con el autor, este hecho de ser sujetos históricos fundamenta nuestra dignidad y nos constituye como gestores de la propia historia. Por otra parte, el a priori antropológico, en cuanto ponerse como valioso, "exige el rescate de la cotidianidad dentro de los marcos de esta última, y es función contingente y no necesaria". (Roig 1982 12). Recubre además las formas lógicas sobre las que se organiza el pensamiento, porque la afirmación del sujeto, su autovaloración, constituye un sistema de códigos de origen socio-histórico que se ponen de manifiesto en la estructura axiológica de todo discurso posible. En este sentido, el a priori se presenta como una natura naturans (creativa, que se gesta) en que lo teleológico resulta decisivo. El acto de autoafirmación como sujetos es raíz de toda objetividad, sin la cual no sería posible la sujetividad misma ${ }^{8}$. El verdadero sujeto de la crítica y de

8 Roig habla de sujetividad y ya no de subjetividad, en la medida que esta última configura una categoría cuya universalidad es a-histórica y opera como sustancia fundante de todo proceso y acontecer histórico. La perspectiva crítica que reconoce la empiricidad de los sujetos, atiende a la trama compleja de relaciones en y desde la cual se afirman o niegan y se configuran modos de sujetivación. 
la autocrítica es un sujeto plural. Además, todo hecho que aparece fuera del sujeto es hecho preinterpretado y en este sentido se puede hablar de "construcción" de la objetividad y posibilidad del discurso.

El lenguaje, entendido como una de las formas -aunque no la únicade objetivación y mediación, es un lugar de "presencia y ausencia" que atraviesa las prácticas humanas, operando como una urdimbre sobre la que se tejen las distintas formas históricas de racionalidad. En cuanto hecho histórico, el lenguaje es manifestación de una realidad social y cultural, muchas veces conflictiva y problemática. Roig se ha referido al lenguaje como una totalidad posible discursiva, que permite aproximarse a lo real y construir nuevos significados y sentidos. A través de la mediación del lenguaje, el sujeto histórico de conocimiento se encuentra con el mundo, lo analiza, lo clasifica, lo interpreta, lo explica, lo construye. Sin embargo:

la realidad que hace de referente es siempre anterior al lenguaje, aunque éste constituye el modo de prioridad del sujeto frente a lo objetivo que es únicamente posible como un sistema de códigos desde los cuales convertimos al mundo en objeto de un sujeto (Roig 1981 78).

Roig no desconoce la deconstrucción iniciada por Foucault ni los desarrollos de los posmodernos, por eso pretende dar un paso más allá con su metodología, a fin de encontrar un acceso al sujeto plural latinoamericano y a la construcción de su historia. Postula que puede haber formas emergentes de racionalidad contra las objeciones hechas a la posibilidad de una filosofía de la sospecha o una "teoría crítica de las ideologías". Una de estas objeciones delata el riesgo de la regresión al infinito, de pretender la filosofía como un simple juego de lenguaje o de ejercer la sospecha para buscar una filosofía fundadora. Roig considera que la "dialéctica real" constituye la praxis que interrumpe cualquier autorreferencialidad del discurso:

Es la praxis la que permanentemente desanuda las aporías de la razón y destruye sus pretendidos universales, como destruye la identidad desde la cual un sujeto ejerce "su" razón. [...] 
Si algo compete a nuestra Historia de las ideas es, precisamente, señalar esos momentos de ruptura de los universales ideológicos y rescatarlos para una filosofía, nuestra Filosofía Latinoamericana, y esa tarea no será posible si caemos en las formas del discurso justificador... (Roig 1993 122).

La conciencia, "antes de ser sujeto, es objeto", es "una realidad social antes que una realidad individual". Es en la "historicidad" o modo de ser histórico que se da la posibilidad misma de afirmarse como sujeto, vale decir, la subjetividad no se podría dar si no se jugaran en un acto de afirmación de tipo histórico. Con lo dicho, la historicidad del acto se da, a la vez, con la historicidad misma del sujeto. No hay sujeto dado, previo a una realidad, sino un sujeto que surge, se construye y se auto-reconoce como parte de una misma realidad (Roig 1993 166).

En Teoría y crítica del pensamiento latinoamericano el mendocino ofrece diferentes ejercicios de lectura en el sentido antes expuesto. Uno de ellos es el que se enfoca en "el problema del ser y del tener" (1981 77 y ss.). Inscripta en una tradición metafísica, la oposición entre lo óntico y lo ontológico articula un problema filosófico de larga data, con intervención en la vida concreta y en nuestras tramas de relaciones sociales. Esta oposición remite al dualismo de la tradición de pensamiento occidental y, como si fuera otra cara de la moneda, replica en conocidos binarismos como alma/cuerpo, espíritu/materia, etc., y determina lo que podríamos llamar formas de la conciencia histórica o de la comprensión de la temporalidad propia del hombre. En el capítulo XI del libro de referencia, Roig analiza dos relatos mitológicos sobre el origen del hombre, uno europeo y otro maya-quiché. El primero es el transcripto por Heidegger en Ser y tiempo, tomado de una fábula de Higinio, y explica la naturaleza dual del hombre como un compuesto de materia y espíritu. En este relato, que es semejante al argumento bíblico, la vida humana resulta dada "desde afuera", por un soplo de Júpiter, sobre un cuerpo hecho de barro (gracias a la tierra) por obra de una especie de artesano llamado Cura. De acuerdo con el texto, al producirse la muerte del ser creado, su espíritu vital debe volver a Júpiter a quien siempre perteneció, y su cuerpo material a la tierra puesto que corresponde a aquello de lo cual fue hecho. El 
otro texto, tomado de la tercera parte del Popol Vuh, relata la creación del hombre en el marco de un tercer intento, en el que los dioses, por fin, logran dar con la materia que entrará en la carne vivificante que es la pasta de maíz. El esfuerzo de los creadores se orientó a la búsqueda de una materia que no era un sustrato a modelar o al que agregar algo. Roig plantea que se da un proceso analítico dual en un caso (fábula de Cura) y un proceso sintético en el otro (hombres de maíz). El segundo relato evidencia que la vida resulta de un "hacerse y gestarse" sin deudas sobrenaturales; la vida, (re)producida a través del trabajo, desarticula la escisión de ser y tener, óntico-ontológica, y desplaza todas las valoraciones negativas de la materia/cuerpo, porque en este radica la posibilidad de la vida.

Roig lee en el contrapunto de estos relatos diferentes criterios de legitimidad. Desde la tradición occidental y su sistema de valores y de derecho, así como sus principios judicativos, el cuerpo representa lo bestial, lo irracional, la barbarie, y en la historia latinoamericana estos fueron asignados a las culturas indígenas de forma homogénea. Pero nuestro autor no propone operar una mera inversión. En el texto maya no hay dualismo. Es en sí mismo una emergencia, algo otro, una codificación otra. Desde él se concibe una legitimidad vital corpórea que, desde sí misma, reclama las condiciones materiales de la vida como criterio político e histórico de desarrollo de la vida humana. La comparación muestra diferentes anclajes axiológicos del reconocimiento.

El relato quiché se encuentra sostenido desde una sujetividad en la que la historicidad se ejerce como praxis de producción y reproducción de la vida. Transformar la naturaleza a través del trabajo para obtener el maíz es tarea creadora respecto de sí mismo. No hay sujetos portadores de alguna trascendencia, sino sujetos empíricos y plurales. No hay extranjeridad, ni espera ni deuda en la relación con la vida porque no hay dualismos originarios (Ripamonti 2014 9).

Como discurso contrario, el Popol Vuh interviene discursos que han naturalizado esquemas valorativos antinómicos de ser y tener, y que han justificado de diverso modo desigualdades e injusticias. 
Las herramientas teóricas y críticas no pueden sortear la discusión sobre las condiciones y posibilidades del saber filosófico como saber práctico social, situado y liberador. El análisis permite visibilizar un sistema de valoraciones en su enclave colonial, es decir, de continuidad como sistema de dependencia. Roig vincula la legitimidad y normatividad del ejercicio de la praxis reflexivo-política con una sujetividad concreta, un nosotros plural y empírico que se valora a sí mismo y a su propia historia, y esta es la de los discursos marginados, silenciados y hasta subalternizados. De aquí que este acto de afirmación es sin duda la piedra de toque de una propuesta metodológica que busca hacerse cargo, en una dimensión política, de una historia de conquista y opresión cuyas marcas encarnan experiencias presentes:

[...] escribir y pensar en América Latina nos lleva ineludiblemente hacia la cuestión de una posible particular manera de pensar y de escribir, no podemos dejar de lado la cuestión de los rasgos de identificación cultural y de su principio configurador, el que no será otro que aquel que se afirma a sí mismo como valioso o se niega como tal (Roig 2008 143).

\section{Homi Bhabha y "el compromiso con la teoría"}

En el contexto de discusión en torno de la modernidad occidental y de ciertas celebraciones posmodernas en la última década del siglo XX, Homi Bhabha ofrece un conjunto de reflexiones y categorías -como las de "mimetismo", "hibridación", ambivalencia"- que nos introducen en un esquema teórico-metodológico y político diferente al de Roig.

En El lugar de la cultura (1994), uno de sus libros más importantes, Homi Bhabha impugna las nociones de pureza cultural, de multiculturalismo y de las identidades híbridas, entendidas como conciliación de opuestos. En particular su capítulo "El compromiso con la teoría" discute acerca del sentido de la teoría: si se reduce a la inversión opresor-oprimido (o centro-periferia, etc.), leída en la praxis política; si se encuentra atrapada en estructuraciones binarias de representación (imperialista); si articula siempre un proyecto utópico de visión tota- 
lizante; si se limita a señalar divisiones geopolíticas y la reproducción del poder hegemónico de Occidente, etc. De otro modo, valen las preguntas: "¿El lenguaje de la teoría es sólo treta de la elite occidental culturalmente privilegiada para producir un discurso del Otro que refuerce su propia ecuación poder-conocimiento?". Y "cuál podría ser la función de una perspectiva teórica comprometida una vez que se toma como punto de partida paradigmático la hibridez cultural e histórica del mundo poscolonial" (Bhabha 2002 41).

La cuestión transita la relación teoría-práctica de un modo particular. En primer lugar, Bhabha parte del reconocimiento de que son como el anverso y reverso de una hoja de papel, ambas son formas de discurso, ambas son una forma de relación, antes que de división. La escritura y la textualidad, su metaforicidad y retórica producen, ponen a disposición objetivos para la acción, pero no al modo de expresión verbal, sintomática o mimética, de segundo orden. De este modo, la acción política, la historia en términos de acontecimientos políticos no está escindida de la historia de sus formas de escritura (Bhabha 43).

Una consecuencia de lo anterior es que el proceso textual se configura como el espacio de escritura de la ambivalencia y la emergencia de diferentes y nuevas proposiciones. No es el lugar de la verdad de uno de los polos de ningún antagonismo, sino de los sentidos producidos y negociados, emergentes y traducidos en un acto de enfrentamiento. No es expresión de una facticidad de la contradicción leída dialécticamente que encarna una concepción teleológica de la historia como escenario de fondo, sino es aquella que supera, desarticula los campos de la oposición (entre sujeto y objeto, entre teoría y razón práctico-política, por ej.) y abre un espacio de traducción e hibridez que puede "regular la estructura diferencial del momento de la intervención" (Bhabha 45).

Las nociones de "negociación" y "traducción" muestran una iteración y diferenciación de apertura en las que no hay algo dado (un referente -nación, pueblo, comunidad, clase, sexualidad-o sentido primordial) que indique el camino correcto o de la verdad, bajo una representación unitaria de la praxis (Bhabha 47). Entonces, cada posición es un proce- 
so de vigilancia conceptual, de traducción y negociación con efectos heterogéneos y desplazamiento de fronteras en las representaciones de grupos y lugares de enunciación, y esto en relaciones agonales de poder. Para Bhabha, en esta emergencia se produce el "momento híbrido" del cambio político como posibilidad. Se aleja cualquier discusión que vincule la producción de la teoría con metanarrativas, o generalidades o discursos disyuntivos que sostengan alguna relación binaria o secuencial con la política (Bhabha 51).

Es interesante cómo Bhabha señala la dificultad de pensar de modo abstracto, binario o dialéctico la relación teoría-práctica. En esta línea, la operación del conocimiento teórico podría, aun considerándose abierto a la diferencia cultural, forcluir al Otro (ubicándolo, citándolo, despojándolo de la posibilidad de significar, de desear, de intervenir, volviéndolo "cuerpo dócil de la diferencia" (Foucault 2002). Este es un rasgo "occidental" del modo de hacer teoría crítica.

Ahora bien, ¿cómo serían posibles otras formas, otros territorios de traducción? Bhabha propone una distinción importante: la de diversidad cultural y diferencia cultural. La primera supone una perspectiva comparativa y relativista elaborada en el desarrollo disciplinar de etnologías y antropologías estructuralistas que, por ejemplo, objetivan la cultura y dejan incólume "la retórica radical de la separación de culturas totalizadas" (Bhabha 55) y los sistemas estables de referencia. Por su parte, la diferencia cultural se hace cargo del límite de la cultura como un "problema de enunciación", de la cuestión de la autoridad para nombrar. Entonces propone un proceso de traducción que abre un tiempo móvil (en contraposición al tiempo teleológico, progresivo o místico fundacional) y un espacio heterogéneo (otro lugar político y cultural que discute, desplaza, hiere, disloca, autoriza otras significaciones). Es el cronotopo de la negociación.

En esta línea, para Bhabha, Fanon, entre otros, como Adrienne Rich o Dereck Walcot, presenta una escritura teórico-práctica de la diversidad. El escritor y psiquiatra caribeño interviene la noción de verdad y lo hace desde un testimonio que interroga la identidad esencialista y binaria (Negro/Blanco, por ejemplo) y se instala en la dislocación 
del sujeto colonial rechazando teorías totalizadoras sobre la opresión (Bhabha 62). Esto lo logra a través de las miradas que desafían la inmediatez o el pretendido carácter de "representación" de lo real por el conocimiento, e interpelan el carácter progresivo y lineal del tiempo histórico.

Cuando en su Piel negra, máscaras blancas Fanon relata la escena en el tren en la que una niña le dice a su madre: "¿Mamá, mira ese negro, jtengo miedo!'", expresa que "ya sabía que existían leyendas, historias, la historia y, sobre todo, la historicidad" (Fanon 1974 103), y que entonces su cuerpo no era una mera imagen o reflejo sino una (sobre)determinación desde el exterior, que lo alcanzaba desde la misma cultura. La cultura sedimentada lo vinculaba de forma radical a la antropofagia, la barbarie, la deficiencia intelectual, la degeneración racial, y desde esa presencia de lo ausente, es decir, de toda la historia de su raza de la que en ese instante debía hacerse cargo. Fanon muestra que no se trata de confrontar una imagen sino de "cuestionar la formación de la autoridad", las condiciones constitutivas de la cultura que se pretende racional, no violenta, autónoma, etc.

La identidad supone un proceso problemático y ambivalente, que posee una dimensión geológica de profundidad y una tensión de sentido y ser, de demanda y deseo. Para Bhabha, Fanon las alcanza cuando inquiere "¿Qué quiere el hombre negro?" (Bhabha 63), porque no hace una pregunta ontológico-esencialista, tampoco pretende una operación lógica axiológica de inversión, mostrando el antagonismo dialéctico opresor/violador- oprimido/alienado. Antes bien, Fanon desarticula los artefactos del discurso colonial, cuestiona el espacio de representación donde el estereotipo es configurado en su relación de contrapunto con el diferente, el Otro. Con elementos del psicoanálisis y desde una analítica del deseo, el autor -nacido en Martinica- redefine las condiciones de constitución de la subjetividad (como proceso de identificación) en el contexto del ejercicio colonial del gobierno y del poder. Esto es que el deseo colonial se articula en relación con el lugar del Otro pero no en un binarismo pendular "Yo colonizado/Otro colonizado" (en el sentido de deseo por afirmar una identidad y ocupar un lugar fijo y determinado, el del Otro/Yo dominador), sino en un espacio de escisión, un 
lugar intermedio /in-between/, productivo, traumático, metonímico", en el que se hace visible (emergente) "el artificio del hombre blanco inscripto en el cuerpo negro" (Bhabha 66), en el que "lo interrogado no es simplemente la imagen de la persona, sino el lugar discursivo y disciplinario desde el que se formulan estratégica e institucionalmente las preguntas de la identidad" (Bhabha 69). Un espacio iterativo de frontera que comparte estructuras simbólicas maniqueas pero de sentidos vicarios, de relaciones de poder culturales y temporales diferentes (Bhabha 77), en los que "el sujeto colonial toma lugar" (Bhabha 80).

Con su relato, Fanon abre un espacio enunciativo y su escritura quiebra, se instala en un espacio de frontera. Le enseña a Bhabha que el acto de enunciación está atravesado por la escritura como estructura de simbolización que no es mímesis (de ningún contexto) ni mero acto comunicativo. No hay contradicción dialéctica, ni binarismo ni reciprocidad. Los espacios de enunciación no se definen solo por polaridades, sino que se sitúan entre la grieta de las fronteras que define cualquier identidad colectiva. Se trata un Tercer Espacio que interviene, como espacio contradictorio, ambivalente, de frontera, intersticial, intermedio indeterminado de los sujetos de enunciación. Es el de las condiciones discursivas que hacen del sentido un campo productivo. Es el campo de la diferencia cultural, el borde de la traducción y negociación como respuesta a prácticas de homogeneización o representaciones identitarias fijas.

El pacto de la interpretación nunca es simplemente un acto de comunicación entre el Yo y el Usted designados en el enunciado. La producción de sentido requiere que esos dos lugares sean movilizados al pasar por un tercer espacio, que representa tanto las condiciones generales del lenguaje y la implicación específica del enunciado en una estrategia performática e institucional la cual no puede, en sí, tener consciencia, lo que esa relación inconsciente introduce es una ambivalencia en el acto de la interpretación (Bhabha 2002 66).

9 Para Bhabha, la metonimia es una figura no de una sustitución simple, sino de un movimiento (parte-todo, identidad-diferencia-alteridad), de una duplicación, una instancia subalterna que tiene y toma un lugar. 
Homi Bhabha sostiene que es necesario comprender que "pensar y escribir son actos de traducción" (Bhabha 2013 80). La traducción genera un espacio dialógico e intercultural, un momento de enunciación y negociación, despojado de su dominio o soberanía en medio de fuerzas asimétricas o desiguales. En los últimos años, Bhabha, reorientó su mirada hacia "la potencia ética que puede asumir el discurso crítico de las humanidades para pensar las escalas globales en las que inscriben los sujetos minoritarios, marginales, carentes de derechos, radicalmente separados de toda instancia de justicia institucional o simbólica" (Siskind 2013 13). En ese borde, migrantes, colonizados y refugiados, en su carácter de nuevos sujetos políticos, reescriben y desnaturalizan las tradiciones nacionales.

La "cultura como signo" articula ese momento intermedio en que la norma del lenguaje, como sistema semiótico -la diferencia lingüística, la arbitrariedad del signo-, se convierte "en una lucha por un derecho a significar histórico y ético" (Bhabha 2002 114). En este contexto, aparece un derecho a narrar que emerge como una apertura simbólica para testimoniar la experiencia y reclamar justicia. Ese derecho puede ejercerse en la medida en que sea habilitado un "espacio público", un "entre" los hombres, que los separa y aproxima en un mundo en común. Y por esto se trata de un lugar de la enunciación, de un compromiso con los derechos del otro.

Hemos visitado, de forma breve, dos prácticas teóricas en las que podemos encontrar contrapuntos, pliegues, categorías complementarias, ontologías en tensión. Pero en este caso lo que nos interesa resaltar es la explicitación de la carnadura de la construcción teórica y cómo ella exige (poseyéndolos) posicionamientos axiológicos y articulación histórico-política.

En Roig encontramos un compromiso ontológico con la dialéctica como modo en que se articula la conflictividad de lo real y discursiva. El análisis de los discursos reconoce, a la vez que produce saberes de denuncia con una función utópica en vista a la transformación del orden vigente, a la emancipación, a la liberación. En sus últimas obras 
propone un matiz al postular que la moral de emergencia, la constitución histórica de una sujetividad plural que se autoafirma como valiosa, juega un papel disruptor frente a totalizaciones opresivas de un sistema hegemónico y con ello la posibilidad de crítica. Algunas preguntas nos permiten inscribir sus reflexiones en los problemas que articularon su propuesta metodológica: ¿cómo podría ejercerse el derecho a leer y hacer "teoría y crítica" sin esta sujetividad? ¿Hasta qué punto el deíctico puede hacerse cargo de la complejidad, la conflictividad, la pluralidad reconocidas? Son preguntas que inauguran otros caminos de discusión y que tienen la ventaja de contar con un legado al que podemos seguir interrogando.

En Bhabha nos encontramos con un compromiso hacia tramas relacionales, señalando espacios de ambivalencia e hibridez que permiten repensar la colonialidad y las posibilidades de socavar formas hegemónicas de la identidad desde acciones emergentes, singulares. Bhabha observa que las interpretaciones de formas de resistencia abierta y por vía de una conflictividad dialéctica podrían corresponder a la ficcionalización de idearios nacionalistas. Para el autor, no hay una división tajante entre colonizador y colonizado, sino una frontera difusa, una relación compleja, mimética, ambivalente $y$, al final, una forma de resistencia por desplazamientos, disolución del discurso occidental por su continua interpretación en un medio social y cultural diverso. De este modo, el análisis de las formas de resistencia debe perseguirse en estas formas de hibridación y microdesplazamientos de la autoridad.

En ambos autores es posible visualizar anclajes teóricos como formas de construcción crítico-política. En Roig, la emergencia es constitutiva de formas de subjetivación plural que se amalgaman históricamente en torno a la función axiológica de la dignidad y la función utópica de liberación. Las formas críticas son de denuncia y resistencia y pueden ser leídas mediante una hermenéutica crítica como historia constructiva, intersubjetiva, de sujeto y objeto, en función de rehabilitar la historia como proyecto humano. En Bhabha, los registros críticos proceden de una agenda de trabajo que supone interpelar el mundo colonial desde escrituras políticas que emergen en espacios amplios, como por ejemplo los del arte y expresiones culturales alternativas 
de minorías. Bhabha apuesta "a encontrar las zonas por donde el funcionamiento mismo de los discursos" produce "subjetividades de posición dispersa", que habilitan desplazamientos, desorganización de sistemas de representación hegemónicos y reposicionamientos (De Oto 2012).

Finalmente, decimos que, en ambos pensadores, se plantea un reclamo por la identidad, en la cual subyace un sujeto que escapa a los esencialismos y las fronteras culturales del discurso de la dependencia o colonial. Roig sostiene la sujetividad empírica del sujeto social e histórico, cuya autoafirmación, bajo formas más o menos auténticas o alienantes, revela su anterioridad-posterioridad con respecto al discurso. En Bhabha podemos interpretar que, en el fondo de la hibridez, hay un reclamo por la identidad, que implica un sujeto como objeto histórico, producto de las singularidades construidas narrativamente desde la interacción entre circunscripciones nacionales y culturales. Sin pretensión de haber agotado este cruce, destacamos en ambos el esfuerzo por desarrollar una analítica epistémica sin renunciar a la performatividad de nuestro quehacer teórico ni al potencial éticopolítico de la dimensión práxica del mismo.

\section{Bibliografía}

Arpini, Adriana. Otros discursos. Mendoza: Editorial FCPyS-Universidad Nacional de Cuyo, 2003.

Bhabha, Homi. El lugar de la cultura. Buenos Aires: Manantial, 2002.

Bhabha, Homi. Nuevas minorías, nuevos derechos. Notas sobre cosmopolitismos vernáculos. Buenos Aires: Siglo XXI Editores, 2013.

Castro-Gómez, Santiago. La hybris del punto cero: ciencia, raza e ilustración en la Nueva Granada (1750-1816). Bogotá: Editorial Pontificia Universidad Javeriana, 2005.

De Oto, Alejandro. "Siempre se trató de la modernidad y del colonialismo: Una lectura entre teorías coloniales desde una perspectiva fanoniana". Cuadernos CILHA 13/2 (2012): 193-214. Recuperado el 13 de agosto de 2013 de http://www.scielo.org.ar/scielo.php?script=sci_arttext\&pid=S1852$96152012000200011 \& \operatorname{lng}=\mathrm{es} \& \mathrm{nrm}=$ iso 
Fanon, Franz. Piel negra, máscaras blancas. Buenos Aires: Schapire Editor, 1974.

Foucault, Michel. Vigilar y castigar. Nacimiento de la prisión. Buenos Aires: Siglo XXI Editores, 2002.

Richard, Nelly. En torno a los estudios culturales. Trayectorias, localidades y disputas. Chile: CLACSO, 2010.

Ripamonti, Paula. "Teoría y crítica: claves epistemológicas para un humanismo crítico". Estudios de filosofía práctica e historia de las ideas 16/1 (2014): 53-61.

Ripamonti, Paula. "El problema del ser y del tener. Reflexiones en perspectiva antropológica". Cuyo 31 (2014) 12. Recuperado el 31 de julio de 2018 de http://bdigital.uncu.edu.ar/6766

Roig, Arturo. Teoría y crítica del pensamiento latinoamericano. México: FCE, 1981.

Roig, Arturo. Narrativa y cotidianidad. La obra de Vladimir Propp a la luz de un cuento ecuatoriano. Quito: Editorial Belén, 1984.

Roig, Arturo. Rostro y filosofía de América Latina. Mendoza: EDIUNC, 1993.

Roig, Arturo. El pensamiento latinoamericano y su aventura. Buenos Aires: El Andariego, 2008.

Roig, Arturo. Historia de las ideas, teoría del discurso y pensamiento latinoamericano. Bogotá: Universidad Santo Tomás, 1993.

Roig, Arturo. Ética del poder y moralidad de la protesta: La moral latinoamericana de la emergencia. Proyecto Ensayo Hispánico, 2000. Recuperado de http://ensayo.rom.uga.edu/filosofos/argentina/roig/referencias.htm

Salazar Bondy, Augusto. ¿Existe una filosofía de nuestra América? México: Siglo XXI Editores, 1968.

Vattimo, Gianni y Rovatti, Pier. El pensamiento débil. Madrid: Cátedra, 1990.

Zea, Leopoldo. Filosofía americana como filosofía sin más. México: Siglo XXI Editores, 1969. 